\title{
Validation of quantitative trait loci for aluminum tolerance in Chinese wheat landrace FSW
}

\author{
Jian Dai · Guihua Bai · Dadong Zhang • \\ Delin Hong
}

Received: 10 January 2012/ Accepted: 22 September 2012/Published online: 21 October 2012

(C) Springer Science+Business Media B.V. (outside the USA) 2012

\begin{abstract}
Aluminum (Al) toxicity is one of the major constraints for wheat production in acidic soils worldwide and use of Al-tolerant cultivars is one of the most effective approaches to reduce $\mathrm{Al}$ damage in the acidic soils. A Chinese landrace, FSW, shows a high level of tolerance to $\mathrm{Al}$ toxicity and a mapping population of recombinant inbred lines (RILs) was developed from a cross between FSW and Al-sensitive US spring wheat cultivar Wheaton to validate the quantitative trait loci (QTL) previously identified in FSW. The mapping population was evaluated for net root growth (NRG) during $\mathrm{Al}$ stress in a nutrient solution culture and hematoxylin staining score (HSS) of root tips after Al stress. After 132 simple sequence repeat (SSR) markers from three chromosomes that were previously
\end{abstract}

\section{J. Dai}

Institute of Food Crops, Jiangsu Academy of Agricultural Sciences, Nanjing 210014, People's Republic of China

J. Dai · G. Bai · D. Zhang

Department of Agronomy, Kansas State University,

Manhattan, KS 66506, USA

J. Dai · D. Hong

State Key Laboratory of Crop Genetics and Germplasm Enhancement, Nanjing Agricultural University,

Nanjing 210095, People's Republic of China

G. Bai $(\bowtie)$

USDA/ARS Hard Winter Wheat Genetics Research Unit and Department of Agronomy, Kansas State University, Manhattan, KS 66506, USA

e-mail: gbai@ksu.edu reported to have the QTLs were analyzed in the population, two QTLs for Al tolerance from FSW were confirmed. The major QTL on chromosome 4DL co-segregated with the Al-activated malate transporter gene (ALMT1), however, sequence analysis of the promoter region (Ups4) of $A L M T 1$ gene indicated that FSW contained a marker allele that is different from the one that was reported to condition $\mathrm{Al}$ tolerance in the Brazilian source. Another QTL on chromosome 3BL showed a minor effect on $\mathrm{Al}$ tolerance in the population. The two QTLs accounted for about $74.9 \%$ of the phenotypic variation for HSS and $72.1 \%$ for NRG and demonstrated an epistatic effect for both HSS and NRG. SSR markers closely linked to the QTLs have potential to be used for marker-assisted selection (MAS) to improve $\mathrm{Al}$ tolerance in wheat breeding programs.

Keywords Chinese landrace - Aluminum tolerance · Simple sequence repeats $\cdot$ QTL mapping

\section{Introduction}

Aluminum (Al) toxicity is a major limiting factor for crop production in acidic soils worldwide. When soil $\mathrm{pH}$ is lower than 5, exchangeable $\mathrm{Al}^{3+}$ is released into the soil solution, inhibiting normal root growth and function (Samac and Tesfaye 2003) and, therefore causes a significant reduction in crop yield. Over $40 \%$ of the world's potentially arable lands are acidic 
(von Uexküll and Mutert 1995; Bot et al. 2000) with up to $60 \%$ of them in developing countries (Kochian et al. 2005). Due to extensive crop production, the area of acidic soils is quickly increasing (Guo et al. 2010). Although irrigation or application of lime to acidic soils can increase soil $\mathrm{pH}$ to relieve Al toxicity, the high cost associated with transportation of lime to destination limits widespread adoption of this practice. Fortunately, significant genetic variation in Al tolerance has been reported in wheat (Stodart et al. 2007; Zhou et al. 2007a; Hu et al. 2008), and growing Al-tolerant cultivars is the most cost-effective approach to improve wheat production in acidic soils.

Inheritance of $\mathrm{Al}$ tolerance in wheat has been extensively studied especially from Brazilian source such as BH1146 and Atlas 66 (Kochian et al. 2005; Samac and Tesfaye 2003; Tang et al. 2002, Ma et al. 2005). However, results on number and locations of genes/quantitative trait loci (QTL) for Al tolerance in wheat are still equivocal. Several studies indicated that Al tolerance in wheat was under monogenic control (Raman et al. 2005; Riede and Anderson 1996), whereas others suggested that multiple genes might be involved in enhancing $\mathrm{Al}$ tolerance in some wheat genotypes (Berzonsky 1992; Cai et al. 2008; Zhou et al. 2007b). Also, the Al tolerance in Asian accessions might not be the same as that from Brazilian sources (Hu et al. 2008; Raman et al. 2008; Zhou et al. 2007a). For example, a Chinese wheat landrace, FSW, showed a similar level of Al tolerance to Atlas 66 as measured by hematoxylin staining, but it had a different haplotype pattern for the markers derived from ALMTl (Hu et al. 2008), a gene encoding an Al-activated malate transporter cloned from the Brazilian source (Sasaki et al. 2004). In addition, different genetic backgrounds may affect expression of tolerance genes that are from the same source. In Atlas 66, a QTL on chromosome 4DL was mapped in both populations of Atlas 66/Century and Atlas 66/Chisholm, but a minor QTL on chromosome 3BL was detected only in Atlas 66/Chisholm (Ma et al. 2005; Zhou et al. 2007b).

Malate release from root tips has been considered as the major mechanism of Al tolerance in wheat (Sasaki et al. 2004). The major QTL on 4DL cosegregated with ALMT1 in several populations (Ma et al. 2005; Raman et al. 2005; Sasaki et al. 2004). Several markers (ALMT1-CAP, SSR3a, and SSR3b) were developed from the gene-coding region for marker-assisted selection (MAS) of the 4DL QTL (Raman et al. 2006).
However, these markers were only effective in some crosses but not others (Zhou et al. 2007b). A new marker has been developed from the promoter region of ALMT1 and reported as a diagnostic marker for $\mathrm{Al}$ tolerance on 4DL (Sasaki et al. 2006; Raman et al. 2008). In FSW, QTLs were initially mapped on 4DL, $3 \mathrm{BL}$ and $2 \mathrm{~A}$ in a population from a cross between FSW and a Chinese line ND35 (Cai et al. 2008). However, these QTLs have not been validated in other populations. The objectives of this study were to validate, in FSW, the effect of Al tolerance QTL that have been previously identified in other sources, to investigate haplotype patterns of ALMT1 marker alleles and to develop high-throughput PCR-based markers for MAS of $\mathrm{Al}$ tolerance in wheat breeding programs.

\section{Materials and methods}

Plant materials and evaluation of $\mathrm{Al}$ tolerance

A mapping population of $217 \mathrm{~F}_{6}$ recombinant inbred lines (RILs) was derived from the cross FSW/Wheaton by the single-seed-descent method. FSW is an Al-tolerant landrace from China, and Wheaton is an Al-sensitive cultivar from Minnesota, USA.

To evaluate Al tolerance of the RILs, wheat seeds were germinated on wet filter papers in petri dishes at $4{ }^{\circ} \mathrm{C}$ for $72 \mathrm{~h}$. Three germinating seeds with similar appearance were transferred onto a nylon wire net on open bottom of a plastic cup. A plastic cup holder was used to support the cups floating on deionized water at room temperature $\left(20-23{ }^{\circ} \mathrm{C}\right)$ with a $16 \mathrm{~h}$ photoperiod using fluorescent lights. Two bubble rods in the water connected to an air pump provided aeration during the culture period. After 48 h of hydroponic culture, the deionized water was replaced with nutrient solution (pH 4.0) consisting of $4 \mathrm{mM} \mathrm{CaCl} 2,6.5 \mathrm{mM} \mathrm{KNO}_{3}$, $2.5 \mathrm{mM} \mathrm{MgCl} 2 \cdot 6 \mathrm{H}_{2} \mathrm{O}, 0.4 \mathrm{mM} \mathrm{NH} \mathrm{N}_{4} \mathrm{NO}_{3}, 0.1 \mathrm{mM}$ $\left(\mathrm{NH}_{4}\right)_{2} \mathrm{SO}_{4}$, and $0.36 \mathrm{mM} \mathrm{AlK}\left(\mathrm{SO}_{4}\right)_{2} \cdot 12 \mathrm{H}_{2} \mathrm{O}$. Reactions of parents and RILs to Al stress were evaluated by measuring root growth during $\mathrm{Al}$ stress and degree of hematoxylin staining of Al-treated root tips. The principal root of each seedling was measured twice after 2 days of hydroponic culture and three-days of Al treatment in nutrient solution to calculate root length difference between the two measurements as net root growth (NRG). Root hematoxylin stain measures the $\mathrm{Al}$ amount that entered into plant roots 
during $\mathrm{Al}$ treatment and has been widely used to measure plant Al tolerance (Ma et al. 2005; Polle et al. 1978). After the second measurement of root length, excess $\mathrm{Al}^{3+}$ on the root surface was rinsed off in deionized water for $1 \mathrm{~h}$, with three replacements. Clean roots were then submerged in a hematoxylin solution containing $0.2 \%$ hematoxylin (w/v) and $0.02 \%(\mathrm{w} / \mathrm{v})$ $\mathrm{NaIO}_{3}$ for $15 \mathrm{~min}$, followed by rinsing the roots with de-ionized water three to four times. The stained root tips of each stained seedling were visually scored as hematoxylin stain score (HSS) using a 1-3 grading scale: no stain on root tips as 1 , lightly stained as 2 , and heavily stained as 3 (Ma et al. 2005). The experiments were repeated twice with three and four replicates (cups), respectively, using a randomized complete block design. In each experiment, an additional replication was used as control in which the culture solution did not contain any $\mathrm{Al}^{3+}$.

After hematoxylin staining, wheat seedlings were grown in a greenhouse for 1 week to harvest leaf tissue of each seedling for DNA isolation. Leaf tissue was collected in a $1.5-\mathrm{mL}$ tube and dried in a freeze drier (Thermo Fisher, Waltham, MA, USA) for 2 days. Tubes containing dried tissue were shaken at 25 times/s for $4 \mathrm{~min}$ in a Mixer Mill (Retsch GmbH, Haan, Germany) with a $3.2 \mathrm{~mm}$ stainless steelbead in each tube.

\section{Marker analysis}

Genomic DNA was extracted using the cetyltrimethyl ammonium bromide (CTAB) method (Saghai-Maroof et al. 1984). A total of 132 pairs of simple sequence repeat (SSR) primers from the chromosomes that were previously reported to have QTLs for Al tolerance were selected to screen parents (Cai et al. 2008; Zhou et al. 2007b; Ma et al. 2005) and polymorphic primers were further analyzed in the $\mathrm{F}_{6}$ RIL population.

For SSR analysis, a $10-\mu \mathrm{L}$ PCR mixture contained $40 \mathrm{ng}$ of template DNA, $2.5 \mathrm{mM} \mathrm{MgCl}_{2}, 200 \mu \mathrm{M}$ each of dNTPs, $50 \mathrm{nM}$ of forward tailed primer, $100 \mathrm{nM}$ of reverse primer and $50 \mathrm{nM}$ of M13 fluorescent-dye labeled primer, $1 \times$ PCR buffer, $1 \mathrm{U}$ of Taq polymerase. A touchdown PCR program was used for PCR amplification, in which the reaction mixture was incubated at $95{ }^{\circ} \mathrm{C}$ for $5 \mathrm{~min}$, then continued for 5 cycles of $1 \mathrm{~min}$ of denaturing at $96{ }^{\circ} \mathrm{C}, 5 \mathrm{~min}$ of annealing at $68{ }^{\circ} \mathrm{C}$ with a decrease of $2{ }^{\circ} \mathrm{C}$ in each subsequent cycle, and $1 \mathrm{~min}$ of extension at $72{ }^{\circ} \mathrm{C}$. For another 5 cycles, the annealing temperature started at $58{ }^{\circ} \mathrm{C}$ for $2 \mathrm{~min}$ with a decrease of $2{ }^{\circ} \mathrm{C}$ for each subsequent cycle. Then, reactions went through an additional 25 cycles of $1 \mathrm{~min}$ at $96{ }^{\circ} \mathrm{C}, 1 \mathrm{~min}$ at $50{ }^{\circ} \mathrm{C}$, and $1 \mathrm{~min}$ at $72{ }^{\circ} \mathrm{C}$ with a final extension at $72{ }^{\circ} \mathrm{C}$ for 5 min. PCR products were analyzed in an ABI PRISM 3730 DNA Analyzer (Applied Biosystems, Foster City, CA, USA).

Data analysis

Marker data collected from the ABI DNA Analyzer were further processed using GeneMarker version 1.5 (SoftGenetics LLC, State College, PA, USA) and rechecked twice manually for accuracy. Genetic linkage groups of SSR markers were constructed using JoinMap3.0 (Van Ooijen and Voorrips 2001). Recombination frequencies were converted into centiMorgans (cM) using the Kosambi function (Kosambi 1944). The threshold value of logarithm of odd (LOD) score was set at 3.0 to claim linkage between markers with a maximum fraction of recombination at 0.4 . WinQTLCart2.5 (Wang et al. 2007) was used for QTL mapping. Genome-wide LOD threshold values for declaring a significant QTL at $P<0.05$ were obtained by running 1,000 times of permutations separately for NRG and HSS traits (Doerge and Churchill 1996). Analysis of variance, heritability of $\mathrm{Al}$ tolerance traits and determination coefficient $\left(R^{2}\right)$ were calculated using SAS system Version 9.1 (SAS Institute, Inc., 2003, Cary, NC, USA).

\section{Results}

Variation in root responses of RILs and their parents to $\mathrm{Al}$ stress

The roots of FSW were longer $(3.3 \mathrm{~cm})$ than those of Wheaton $(0.6 \mathrm{~cm})$ after $72 \mathrm{~h}$ of hydroponic culture in a nutrient solution containing $0.36 \mathrm{mM} \mathrm{Al}^{3+}$. After 3 days of $\mathrm{Al}$ treatment, the root tips of Wheaton were fully stained by hematoxylin (grade 3 ), whereas those of FSW were not stained (grade 1). In non-Al controls, Wheaton and FSW showed similar root lengths and hematoxylin stain scores. Therefore, the Al concentration used in this study was appropriate for differentiating the tolerant genotypes from the sensitive genotypes by measuring either NRG or HSS. 
The frequency distribution of NRG of the RILs under Al stress was continuous with the major peak toward Wheaton (Fig. 1). A similar distribution was observed for HSS (Fig. 2). A highly significant correlation coefficient $(r=0.87, \quad P<0.01)$ was observed between NRG and HSS in the mapping population. The correlations between untreated root length and NRG, HSS were low $(r=0.21$ and 0.20 , respectively) and not significant in the RIL population. Therefore, NRG and HSS were independent of variation in root growth under non-Al-stressed conditions among RILs. Variance analysis showed that the effects of RILs were significant in both NRG and HSS (Table 1$)$. Heritability was high for both NRG (0.88) and HSS (0.87), and thus, only a few genes may be involved in $\mathrm{Al}$ tolerance in the population.

\section{QTL for Al tolerance in FSW}

After 132 SSR primers were screened, 35 were polymorphic between parents and further analyzed in the $F_{6}$ RIL population. A total of 24 markers were mapped in the 3 linkage groups spanning $138.7 \mathrm{cM}$ of genetic distance. The first group had 9 SSRs spanning $41.8 \mathrm{cM}$ on chromosome 3BL, the second had 12 SSRs spanning $88.2 \mathrm{cM}$ on chromosome 4DL, and the third had only 3 SSRs spanning $8.7 \mathrm{cM}$ on chromosome $2 \mathrm{~A}$. These three linkage maps were used for further QTL analysis. Interval mapping identified two QTLs for Al tolerance on chromosomes 4DL and 3BL. The QTL on 4DL showed a major effect on both NRG and HSS, whereas the QTL on 3BL had a minor effect on NRG and HSS (Fig. 3). The QTL on 4DL co-segregating

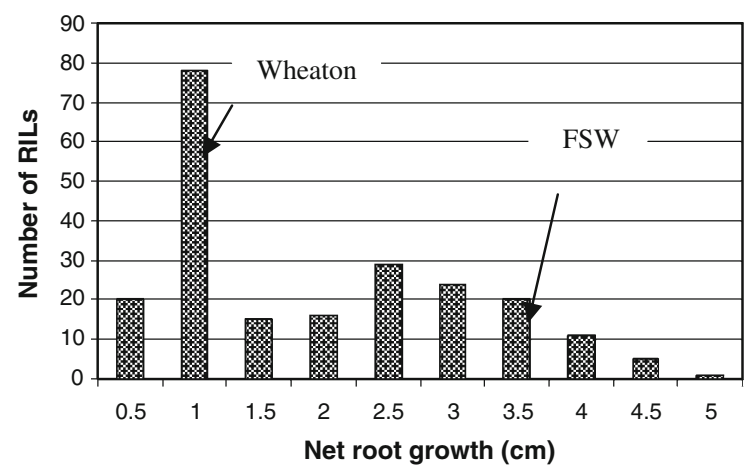

Fig. 1 Frequency distribution of net root growth (NRG) for 217 F6 recombinant inbred lines from the cross FSW/Wheaton after $72 \mathrm{~h}$ of Al stress. Arrows point to mean NRG for parents FSW (right) and Wheaton (left)

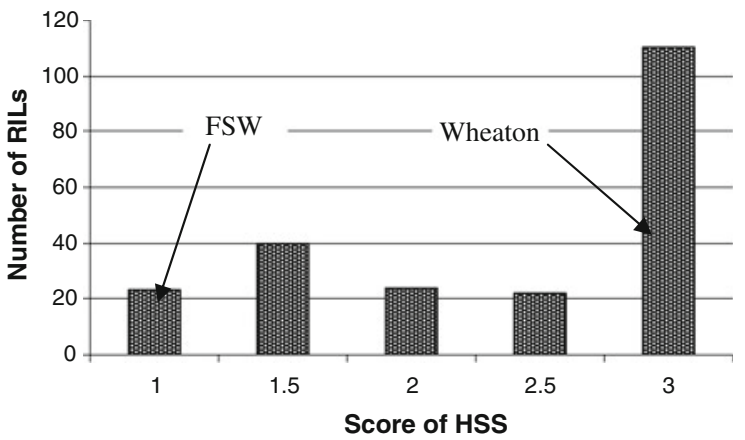

Fig. 2 Frequency distribution of hematoxylin stain score (HSS) for RILs from the cross FSW/Wheaton after $72 \mathrm{~h}$ of Al stress. Arrows point to mean HSS of HSS for parents Wheaton (right) and FSW (left)

Table 1 Variance components and heritability for net root growth (NRG) and hematoxylin stain score (HSS) in the recombinant inbred population derived from the cross FSW/ Wheaton

\begin{tabular}{lrrrrr}
\hline Source & DF & \multicolumn{1}{l}{ SS } & MS & $F$ value & $\mathrm{h}^{2}$ \\
\hline NRG & & & & & \\
Experiment & 1 & 97.39 & & 97.39 & $298.89^{* *}$ \\
RILs & 216 & 1929.00 & 8.93 & $27.41^{* *}$ & 0.88 \\
Experiment & 216 & 236.69 & 1.10 & $3.36^{* *}$ & \\
$\quad$ *RILs & & & & & \\
Error & 1,057 & 344.41 & 0.33 & & \\
Total & 1,490 & 2607.39 & & & \\
HSS & 1 & & & & \\
Experiment & 216 & 2.87 & 2.87 & $17.49^{* *}$ & \\
RILs & 216 & 892.45 & 4.13 & $25.21^{* *}$ & 0.87 \\
Experiment & 1,059 & 120.26 & 0.56 & $3.40^{* *}$ & \\
$\quad *$ RILs & & & & & \\
Error & 1,492 & 173.56 & 0.16 & & \\
Total & & 1189.14 & & & \\
\hline
\end{tabular}

** indicates significant $F$-value at $P<0.01$

with $X w m c 331$ was flanked by the markers Xups 4 and $X g d m 125$, with $R^{2}$ values of $65.7 \%$ for NRG and $70.1 \%$ for HSS, and with LOD values 57.8 for NRG and 64.9 for HSS. The QTL on 3BL was flanked by the markers Xbarc344 and Xbarc164, with $R^{2}$ values of $3.7 \%$ for NRG and $2.7 \%$ for HSS, and with LOD values 7.8 for NRG and 6.7 for HSS (Table 2).

To analyze the effect of the two QTLs on $\mathrm{Al}$ tolerance, the closest markers Xwmc331 on 4DL and Xbarc344 on 3BL were selected to represent the two QTLs (Fig. 4). Four possible combinations of the two QTLs are: 4DL+/3BL+, 4DL+/3BL-, 4DL-/ 

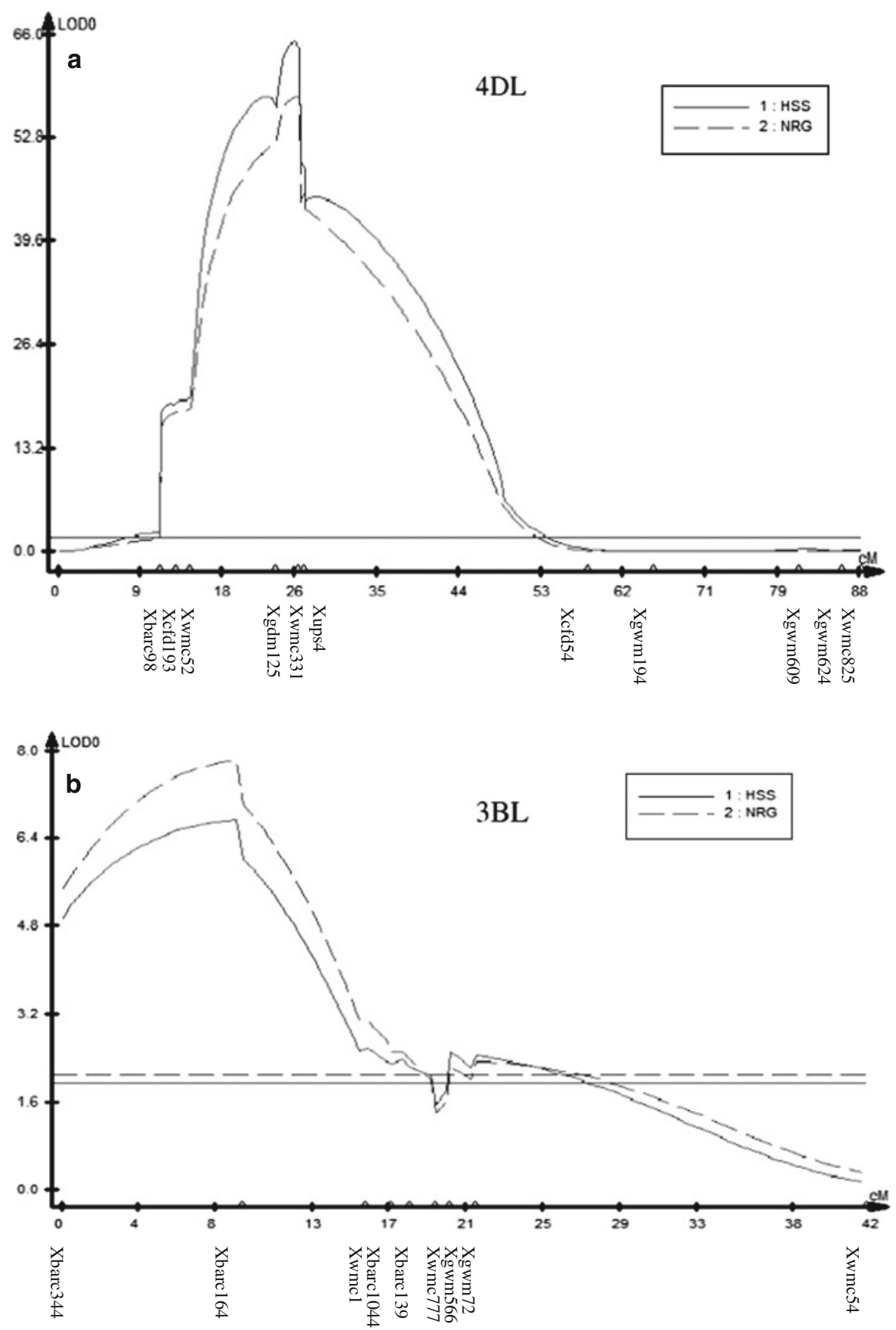

Fig. 3 a Major QTL on 4DL and $\mathbf{b}$ a minor QTL on 3BL

$3 \mathrm{BL}+, 4 \mathrm{DL}-/ 3 \mathrm{BL}-$, in which $4 \mathrm{DL}+$ and $3 \mathrm{BL}+$ represent $\mathrm{Al}$ tolerance marker alleles of QTLs from $4 \mathrm{DL}$ and $3 \mathrm{BL}$ of FSW, respectively, and $4 \mathrm{DL}-$ and $3 \mathrm{BL}-$ represent corresponding $\mathrm{Al}$-sensitive marker alleles from Wheaton. Mean comparisons of these genotype combinations indicated that combination of these two QTLs increased NRG by $2.6 \mathrm{~cm}$ and decreased HSS by 1.8 relative to the genotype with Al-sensitive haplotype of the marker alleles on both 4DL and 3BL. In the presence of the Al-tolerance 
Table 2 Flanking markers, logarithm of odd (LOD) values, and coefficients of determination $\left(R^{2}\right)$ of QTLs for hematoxylin stain score (HSS) and net root growth (NRG) evaluated in the recombinant inbred population derived from the cross FSW/Wheaton

\begin{tabular}{|c|c|c|c|c|c|c|}
\hline \multirow[t]{2}{*}{ Chromosome } & \multirow[t]{2}{*}{ Marker interval } & \multirow[t]{2}{*}{ Experiment } & \multicolumn{2}{|l|}{ HSS } & \multicolumn{2}{|l|}{ NRG } \\
\hline & & & LOD & $R^{2}$ & LOD & $R^{2}$ \\
\hline \multirow[t]{3}{*}{$4 \mathrm{DL}$} & \multirow[t]{3}{*}{ Xgdm125-Xwmc331 } & I & 53.18 & 62.17 & 48.69 & 60.98 \\
\hline & & II & 51.20 & 63.29 & 47.50 & 56.60 \\
\hline & & Mean & 64.86 & 70.05 & 57.80 & 65.68 \\
\hline \multirow[t]{3}{*}{$3 \mathrm{BL}$} & \multirow[t]{3}{*}{ Xbarc344-Xbarc164 } & I & 5.89 & 2.77 & 3.96 & 1.84 \\
\hline & & II & 4.96 & 2.14 & 7.65 & 5.56 \\
\hline & & Mean & 6.72 & 2.74 & 7.80 & 3.70 \\
\hline \multirow[t]{3}{*}{ Total } & & I & & 67.55 & & 65.51 \\
\hline & & II & & 67.01 & & 64.50 \\
\hline & & Mean & & 74.94 & & 72.12 \\
\hline
\end{tabular}

marker allele on 4DL, the 3BL marker allele associated with $\mathrm{Al}$ tolerance increased $\mathrm{NRG}$ by $1 \mathrm{~cm}$, whereas it only increased about $0.2 \mathrm{~cm}$ without the 4DL marker allele linked to Al tolerance. Similarly, the tolerance allele on 3BL decreased by 0.6 in HSS in the presence of 4DL allele and very little when marker allele associated with $\mathrm{Al}$ tolerance on 4DL was absent (Fig. 4). These two QTLs for Al tolerance appeared to have epistatic effect on NRG and HSS.

Two ALMT1 gene markers, Xups4 and Xssr3a, were polymorphic between the two parents and they were used to analyzed the RILs. Xups 4 amplified two different sizes of amplicons between Al-tolerant FSW and sensitive Wheaton. The size of 471 bp allele was

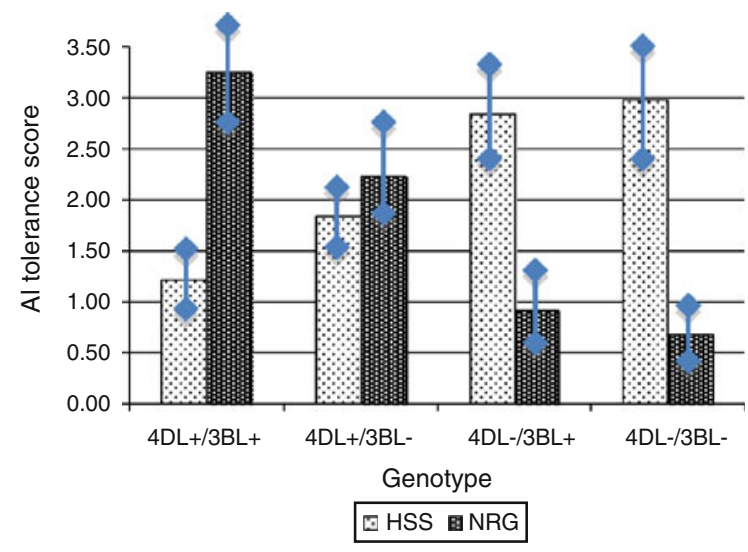

Fig. 4 Effect of 4DL and 3BL QTLs on Al tolerance in RIL population from the cross FSW/Wheaton. 4DL+ and 3BL+ represent $\mathrm{Al}$ resistant marker alleles of the QTLs from 4DL and $3 \mathrm{BL}$ of FSW, respectively, and $4 \mathrm{DL}-$ and $3 \mathrm{BL}-$ represent $\mathrm{Al}$ sensitive marker alleles of the two QTLs from Wheaton, respectively. NRG and HSS represent net root growth $(\mathrm{cm})$ and hematoxylin staining score, respectively. Lines are standard deviations associated with Al-tolerant genotypes, whereas the 440 bp allele was associated with Al-sensitive genotypes in the population. The correlation of coefficients of the Xups 4 allele with HSS and NRG were 84 and $83 \%$, respectively, in the RIL population. Xssr3a amplified a $225 \mathrm{bp}$ fragment in FSW and a $223 \mathrm{bp}$ fragment in Wheaton. The correlation of coefficients of the Xssr3a allele with HSS and NRG are 83 and $82 \%$, respectively, in the RIL population. Xssr $3 b$ did not amplify any alleles in two parents and the RILs, and thus it was not analyzed further.

\section{Discussion}

Evaluation of $\mathrm{Al}$ tolerance

Al tolerance of wheat is usually evaluated in acidic soils under field conditions. Inconsistent phytotoxicity and $\mathrm{pH}$ value among the plots may induce significant environmental variations (Ma et al. 2005). Thus field tests may not provide consistent results for the proper comparison. An alternative method for evaluating $\mathrm{Al}$ tolerance using hydroponic culture provides a strict control in nutrient solution containing a toxic level of $\mathrm{Al}$ and $\mathrm{pH}$, and can provide non-destructive measurements in large populations. Therefore, it has been widely used in genetic studies (Polle et al. 1978; Ma et al. 2006; Guo et al. 2007; Navakode et al. 2009). With this method, NRG of Al-stressed seedling has been measured to reflect plant tolerance to $\mathrm{Al}$ toxicity in several studies (Parker and Pedler 1998; Zhou et al. 2007a). Hematoxylin staining can measure the extent of $\mathrm{Al}$ accumulation in root cells and has been widely used to evaluate $\mathrm{Al}$ tolerance in several crops 
(Delhaize et al. 1993; Cancado et al. 1999; Anas 2000). In this study, both NRG and HSS were used to measure $\mathrm{Al}$ tolerance of parents and the RIL mapping population. A high correlation between the two traits was observed $(r=0.87, P<0.01)$.

The two parents showed a large contrast in NRG and HSS. Significant variations in NRG and HSS were observed among the RILs with high heritability of both measurements. QTL for HSS and NRG were mapped on the same chromosome positions. The two QTLs on 4DL and 3BL together accounted for about $74.9 \%$ of the phenotypic variation for HSS and $72.1 \%$ for NRG. Results suggested that both HSS and NRG were reliable measurements for the mapping study of Al tolerance.

\section{Inheritance of $\mathrm{Al}$ tolerance in wheat}

Wheat is the best-characterized species and genetic system for analyzing Al tolerance (Kochian et al. 2004). Several studies that used the Brazilian sources of tolerance such as BH1146 and Atlas 66 postulated that $\mathrm{Al}$ tolerance segregated as a single dominant locus. Riede and Anderson (1996) first mapped the gene as $\mathrm{Alt}_{\mathrm{BH}}$ on 4DL of BH1146 using restricted fragment length polymorphism and concluded that this gene was fully responsible for $\mathrm{Al}$ tolerance in BH1146. Ma et al. (2005) identified a QTL for Al tolerance on the same chromosome region of Atlas 66 using a RIL population from Atlas 66/Century. However, several other studies suggested that at least two loci might be involved in Al tolerance in Atlas 66 (Garvin and Carver 2003; Tang et al. 2002; Zhou et al. 2007b). Several studies using wheat genetic stocks including deletion lines, nullitetrasomics, and ditelosomics also supported multigenic controls of $\mathrm{Al}$ tolerance (Aniol and Gustafson 1984; Aniol 1990; Ma et al. 2006; Papernik et al. 2001). In this study, two QTLs on 4DL and 3BL were identified, which agrees with Zhou et al. (2007b). In that study, the minor QTL on 3BL of Atlas 66 accounted for $11.1 \%$ of the phenotypic variation for HSS and $8.6 \%$ for NRG. Cai et al. (2008) used a population developed by crossing FSW to a Chinese dwarf line ND35 and reported that the QTL on 3BL showed a major effect on Al tolerance with $R^{2}=47.0 \%$ for HSS and $41.7 \%$ for NRG. However, the QTL showed a much smaller effect on Al tolerance in the Wheaton background $\left(R^{2}=2.7\right.$ and $3.7 \%$ for HSS and NRG, respectively) in this study although the QTL on 3BL in this study was mapped on the same chromosome region as that reported by Cai et al. (2008). This 3BL QTL was detected in different sources of Al-tolerant germplasm and same source in different genetic backgrounds, and therefore is more likely a 'real' QTL. However this QTL appears to be less stable than the one on 4DL. The minor QTL for HSS and NRG on chromosome 2A reported by Cai et al. (2008) was not detected in this study although the markers linked to the QTL reported by Cai et al. (2008) were polymorphic in the current population. It is also possible that other minor genes may be involved in $\mathrm{Al}$ tolerance in the population because only three previously reported chromosome regions were screened in this study.

\section{Marker allele for ALMT1 in FSW}

ALMT1 on 4DL has been considered a major contributor to Al tolerance in several germplasm lines (Raman et al. 2005; Ma et al. 2005; Sasaki et al. 2004; Zhou et al. 2007b) and it has been used as a major $\mathrm{Al}$ tolerance gene in MAS in breeding programs where $\mathrm{Al}$ tolerance is a major breeding objective. Raman et al. (2005) studied the structure and chromosomal location of ALMT1 and concluded that $\mathrm{Al}$ tolerance in a diverse range of wheat genotypes is primarily conditioned by $A L M T 1$.

In this study, the QTL with the largest effect on Al tolerance in FSW was also mapped to a similar location as that in Atlas 66 (Ma et al. 2005; Zhou et al. 2007b). ALMT1 as represented by Xups 4 was also mapped in the QTL region in FSW that confirmed the previous report (Cai et al. 2008). Interestingly, Xwmc331 was the closest marker for the QTL, not Xups4, and Xgdm125 and Xups4 flanked the QTL for both traits, which agrees with Cai et al. (2008) who mapped the major QTL between Xgdm125 and Xups 4 in FSW/ND35 population. Xups 4 is a sequence upstream from ALMT1 in wheat.

Sasaki et al. (2006) further investigated the promoter structure of ALMT1 and concluded that expression of Al tolerance is mainly conditioned by the variation in promoter size. The germplasm that amplified large fragments (706-1,229 bp) by Xups 4 from the promoter region of $A L M T 1$ were considered Al tolerant whereas the germplasm that amplified 469 bp or smaller fragments were considered to be sensitive to Al stress. In this study, FSW amplified a 
471 bp amplicon, a sensitive allele based on Sasaki et al. (2006), but showed Al tolerance. However, Sasaki et al. (2006) also noticed that Japanese lines showed a weak correlation between ALMT1 expression and Al tolerance. This suggested that the mechanisms of $\mathrm{Al}$ tolerance in FSW might be different from that of the Brazilian source. FSW may have a different mechanism in regulating expression of $A L M T 1$ or the ALMT1 promoter may not be the key molecular regulator for the ALMT1 expression in FSW. It is also possible that some other factors may be involved in the control of malate efflux in addition to the level of ALMT1 expression (Sasaki et al. 2006; Raman et al. 2005).

All three 4DL markers (Xwmc331, Xups4 and $X g d m 125)$ that were polymorphic in FSW/Wheaton population were mapped in the QTL region showing a very large effect on $\mathrm{Al}$ tolerance. Xwmc331 and $X g d m 125$ are SSR markers and suitable for highthroughput analysis, and therefore, they can be used for MAS. Xups4 is a gene marker, and should be the best marker for MAS. Al tolerant FSW amplified a smaller fragment of Xups4 (453 bp after removal of a $18 \mathrm{bp} \mathrm{M13} \mathrm{tail)} \mathrm{that} \mathrm{was} \mathrm{considered} \mathrm{the} \mathrm{allele}$ associated with Al-sensitivity (Sasaki et al. 2006) in Brazilian sources. Therefore the amplicon size of Xups 4 cannot be used as the only selection criterion for the 4DL QTL resistance allele. However, it still is an informative marker for the 4DL QTL if it is polymorphic in a breeding population. Previously, a cleaved amplified polymorphism (CAP) marker has been used as diagnostic marker for the 4DL QTL in markerassisted breeding for $\mathrm{Al}$ tolerance (Zhou et al. 2007b; Ma et al. 2005), but it requires an additional step of restriction digestion after PCR amplification (Raman et al. 2006). Thus, it can be replaced with Xwmc331 or Xups 4 when FSW is used as an Al-tolerant source.

In a summary, two QTLs for Al tolerance previously mapped in other populations were confirmed in a new FSW population. The major QTL on chromosome 4DL co-segregated with the Al-activated malate transporter gene (ALMT1), but it was a different allele from the one previously reported to condition $\mathrm{Al}$ tolerance, was identified in FSW. Another QTL on chromosome 3BL showed a minor effect on $\mathrm{Al}$ tolerance in the population. The two QTLs accounted for about $74.9 \%$ of the phenotypic variation for HSS and $72.1 \%$ for NRG. DNA markers closely linked to the QTLs should be useful for MAS to improve Al tolerance in wheat breeding programs.

Acknowledgments This project was partially supported by the National Research Initiative Competitive Grants CAP project 2011-68002-30029 from the USDA National Institute of Food and Agriculture and the scholarship to the first author from State Administration of Foreign Experts Affairs, China (no. CG2008320006). The authors would like to thank Dr. Paul St. Amand, USDA Central Small Grain Genotyping Center, and Dr. Chengsong Zhu, Department of Agronomy, Kansas State University, Manhattan KS, for technical assistance. Mention of trade names or commercial products in this article is solely for the purpose of providing specific information and does not imply recommendation or endorsement by the U.S. Department of Agriculture. USDA is an equal opportunity provider and employer. This is contribution no. 12-413-J from the Kansas Agricultural Experiment Station, Manhattan, KS.

\section{References}

Anas YT (2000) Screening of Al-tolerant sorghum by hematoxylin staining and growth response. Plant Prod Sci 3:246-253

Aniol A (1990) Genetics of tolerance to aluminum in wheat (Triticum aestivum L. Thell). Plant Soil 123:223-227

Aniol A, Gustafson JP (1984) Chromosome locations of genes controlling aluminum tolerance in wheat, rye, and triticale. Can J Genet Cytol 26:701-705

Berzonsky WA (1992) The genomic inheritance of aluminum tolerance in 'Atlas 66' wheat. Genome 35:689-693

Bot AJ, Nachtergaele FO, Young A (2000) Land resource potential and constraints at regional and country levels. Food and Agricultural Organization of the United Nations, Rome, pp 1-114

Cai SB, Bai GH, Zhang DD (2008) Quantitative trait loci for aluminum resistance in Chinese wheat landrace FSW. Theor Appl Genet 117:49-56

Cancado GMA, Loguercio LL, Martins PR, Parentoni SN, Paiva E, Borem A, Lopes MA (1999) Hematoxylin staining as a phenotypic index for aluminum tolerance selection in tropical maize (Zea mays L.). Theor Appl Genet 99:747-754

Delhaize E, Craig S, Beaton CD, Bennet RJ, Jagadish VC, Randall PJ (1993) Aluminum tolerance in wheat (Triticum aestivum L.): uptake and distribution of aluminum in root apices. Plant Physiol 103:685-693

Doerge R, Churchill G (1996) Permutation tests for multiple loci affecting a quantitative character. Genetics 142:285-294

Garvin DF, Carver BF (2003) Role of genotypes tolerant of acidity and aluminum toxicity. In: Rengel Z (ed) Handbook of soil acidity. Marcel Dekker, New York, pp 387-406

Guo PG, Bai G-H, Carver B, Li R-H, Bernardo A, Baum M (2007) Transcriptional analysis between two wheat nearisogenic lines contrasting in aluminum tolerance under aluminum stress. Mol Genet Gen 277:1-12

Guo JH, Liu XJ, Zhang Y, Shen JL, Han WX, Zhang WF, Christie P, Goulding KWT, Vitousek PM, Zhang FS (2010) 
Significant acidification in major Chinese croplands. Science 327:1008-1010

Hu SW, Bai GH, Carver BF, Zhang DD (2008) Diverse origins of aluminum-resistance sources in wheat Theor. Appl Genet 118:29-41

Kochian LV, Hoekenga OA, Piñeros MA (2004) How do crop plants tolerate acid soils? Mechanisms of aluminum tolerance and phosphorous efficiency. Annu Rev Plant Biol 55:459-493

Kochian LV, Piñeros MA, Hoekenga AO (2005) The physiology, genetics and molecular biology of plant aluminum resistance and toxicity. Plant Soil 274:175-195

Kosambi DD (1944) The estimation of map distances from recombination values. Ann Eugen 12:172-175

Ma HX, Bai GH, Carver BF, Zhou LL (2005) Molecular mapping of a quantitative trait locus for aluminum tolerance in wheat cultivar Atlas 66. Theor Appl Genet 112:51-57

Ma HX, Bai GH, Lu WZ (2006) Quantitative trait loci for aluminum resistance in wheat cultivar Chinese Spring. Plant Soil 283:239-249

Navakode S, Weidner A, Lohwasser U, Röder MS, Börner A (2009) Molecular mapping of quantitative trait loci (QTLs) controlling aluminium tolerance in bread wheat. Euphytica 166:283-290

Papernik LA, Bethea AS, Singleton TE, Magalhaes JV, Garvin DF, Kochian LV (2001) Mechanistic basis of Al sensitivity in the ditelosomic lines of Chinese Spring wheat. Planta 212:829-834

Parker DR, Pedler JF (1998) Probing the "malate hypothesis" of differential aluminum tolerance in wheat by using other rhizotoxic ions as proxies for Al. Planta 205:389-396

Polle E, Konzak CF, Kittrick JA (1978) Visual detection of aluminum tolerance levels in wheat by hematoxylin staining of seeding roots. Crop Sci 18:823-827

Raman H, Zhang KR, Cakir M, Appels R, Garvin DF, Maron LG, Kochian LV, Moroni JS, Raman R, Imtiaz M, DrakeBrockman F, Waters I, Martin P, Sasaki T, Yamamoto Y, Matsumoto H, Hebb DM, Delhaize E, Ryan (2005) Molecular characterization and mapping of ALMT1, the aluminium-tolerance gene of bread wheat (Triticum aestivum L.). Genome 48:781-791

Raman H, Raman R, Wood R, Martin P (2006) Repetitive indel markers within the ALMT1 gene conditioning aluminium tolerance in wheat (Triticum aestivum L.). Mol Breeding 18:171-183

Raman H, Ryan PR, Raman R, Stodart BJ, Zhang KL, Martin P, Wood R, Sasaki T, Yamamoto Y, Mackay M, Hebb DM, Delhaize E (2008) Analysis of TaALMT1 traces the transmission of aluminum resistance in cultivated common wheat (Triticum aestivum L.). Theor Appl Genet 116: 343-354

Riede CR, Anderson JA (1996) Linkage of RFLP markers to an aluminum tolerance gene in wheat. Crop Sci 36:905-909

Saghai-Maroof MA, Soliman K, Jorgensen RA, Allard RW (1984) Ribosomal DNA spacer-length polymorphisms in barely: Mendelian inheritance, chromosomal location, and population dynamics. Proc Natl Acad Sci USA 81: 8014-8018

Samac DA, Tesfaye M (2003) Plant improvement for tolerance to aluminum in acid soil-a review. Plant Cell Tissue Organ Cult 75:189-207

Sasaki T, Yamamoto Y, Ezaki B, Katsuhara M, Ahn SJ, Ryan PR, Delhaize E, Matsumoto H (2004) A wheat gene encoding an aluminum-activated malate transporter. Plant J 37:645-653

Sasaki T, Ran PR, Delhaize E, Hebb DM, Ogihara Y, Kawaura K, Noda K, Kojima T, Toyoda A, Matsumoto H, Yamamoto Y (2006) Sequence upstream of the wheat (Triticum aestivum L.) ALMT1 gene and its relationship to aluminum resistance. Plant Cell Physiol 47(10): 1343-1354

Stodart BJ, Raman H, Coombes N, Mackay M (2007) Evaluating landraces of bread wheat Triticum aestivum $\mathrm{L}$. for tolerance to aluminum under low $\mathrm{pH}$ conditions. Genet Resour Crop Evol 54:759-766

Tang Y, Garvin DF, Kochian LV, Sorrells ME, Carver BF (2002) Physiological genetics of aluminum tolerance in the wheat cultivar Atlas 66. Crop Sci 42:1541-1546

van Ooijen JW, Voorrips RE (2001) JoinMap® 3.0. Software for the calculation of genetic linkage maps. Plant Res. Int, Wageningen

von Uexküll HR, Mutert E (1995) Global extent, development and economic impact of acid soils. In: Date RA, Grundon NJ, Rayment GE, Probert ME (eds) Plant-soil interactions at low pH: principles and management. Kluwer Academic Publisher, Boston

Wang S, Basten CJ, Zeng ZB (2007) Windows QTL Cartographer 2.5. Department of Statistics, North Carolina State University, Raleigh. http://statgen.ncsu.edu/qtlcart/WQTL Cart.htm

Zhou LL, Bai GH, Carver BF (2007a) Identification of new sources of aluminum resistance in wheat. Plant Soil 297:105-118

Zhou LL, Bai GH, Ma HX, Carver BF (2007b) Quantitative trait loci for aluminum resistance in wheat. Mol Breeding 19:153-161 